New Zealand journal of industrial relations, 1984, 9, 49-50

\title{
REPLY
}

\section{The treatment of industrial relations in three major New Zealand newspapers: a reply}

\author{
Raymond Harbridge*
}

Warren Page is a very senior journalist in New Zealand and the comments he has made provide a valuable insight into the difficulties that newspapers have with reporting industrial relations. He has made a number of defences on behalf of the industry for my research results, yet has not criticised the results themselves, only my interpretation of them. I would like to offer the following by way of reply.

Some years ago, I joined the Wellington Marathon Clinic and spent an enjoyable, though difficult, season running under a system that could best be described as running-by-objectives. The thrust of the clinic was in setting and meeting daily and weekly running mileage targets. The President of the Clinic stated that the purpose of weekly running targets was to actually run those distances. If goals were to be met and a marathon eventually completed, it was critical that weekly targets were run. Taking into account what would have been run had the weather been perfect, shins not been sore, and tiredness not been overpowering on 2 days, was not allowed.

My approach to the researching of industrial relations reporting in newspapers has taken the same approach as that of the Marathon Clinic President. I set out to examine the items that actually appeared in print, not the ones that journalists would have written if they had received the full, frank co-operation of industrial relations protagonists, if stories had "broken" at a time suitable to the commercial needs of the newspaper, if industrial journalits did not take annual leave, if the issues to be reported were simple rather than complex, and if each item produced by the journalist neatly fitted the sub-editor's page layout requirements.

Warren Page defends the defects in industrial relations reporting that are evident from my research on 2 grounds. First, that reporting industrial relations is difficult for the above reasons (summarised from his comment) and second, that the media has commercial criteria to consider - nobody wants to be second with the "news". I am sure that both these factors can place difficulties in the way of the journalist. The issue is overcoming those difficulties and improving the quality of reporting.

The approach taken in my research was a behavioural approach based on measurement of the indisputable features of industrial reporting. Page argues that this leads to an omission of some crucial factors and considerations. It may do that - but my method ensured that the features identified were objective. Imagine the response had I attempted to make value judgements regarding the accuracy or "newsworthiness" of a specific item. Journalists, the practitioners involved and academics would have immense difficulty agreeing with each other as to whether particular items were newsworthy and accurately reported.

The subjective judgement referred to by Page is avoided by the behavioural approach adopted. Industrial relations items were compared with all other types of non-industrial items. Conclusions on trivialisation and sensationalism were based on the observation of

* Lecturer, Industrial Relations Centre, Victoria University of Wellington. 
larger headlines over shorter items. This observation was highly (statistically) significant . over the complete range of industrial and non-industrial items - not something observed occasionally.

Industrial relations items are short on content and detail yet attention is drawn to them through large headlines. Both these features are more likely related to the behaviour of the sub-editor rather than that of the journalist. This has been recognised by most people reading my results, yet curiously, Page fails to address himself to that issue. The question here is why are industrial items treated differently from other items? I accept that industrial journalists may "write succinctly", and that sub-editors may, by honing, "compress all vital points into a few words", but why do these same sub-editors not exhibit the same honing skills with other types of items? The simple fact of the matter is that industrial stories are on average consistently shorter than other items yet have, on average, larger headlines. The statistics used in the original research paper indicate that this is a regular pattern - not something observed occasionally, and Page simply fails to address himself to the issue of why sub-editors treat industrial items differently from other types of items.

Page justifies reportage of industrial conflict on the grounds that work stoppages can influence people's incomes and/or convenience. Accidents at work and industrial disease lead annually to far more working days lost than does industrial conflict and in planning this research project a separate content category was developed for industrial health and safety issues. The category was eventually abandoned as a separate entity because such items occurred so infrequently. Yet, on average, one worker is killed through a work accident somewhere in New Zealand every second day. If influences on people's incomes and convenience are criteria for "newsworthiness" then the absence of health and safety reporting is even more astonishing.

The purpose of the research project was first, to encourage discussion about the way the media reports industrial relations and second, to assist journalists and sub-editors to improve the quality of industrial reporting. The advantage of the behavioural approach adopted is that frequently mere indentification of the character of a behaviour (in this case industrial reporting) can lead directly to change. In that regard I believe that the research has already been of value. In referring to the wage-tax trade-off talks and the lack of information and explanation offered by the papers, Page states that the talks are "behind closed doors with the participants bound to confidentiality". Tripartite wage policy talks are the concern of the whole country, not just a select group of 10 to 12 middle-aged Pakeha men, and despite their long running nature, the results are most likely to be successfully implemented if widespread discussion and debate has taken place in the community about the issues behind the talks. The influence of these talks on people's incomes and convenience will be far higher than the odd stoppage by bus drivers.

Fortunately, one of Page's colleagues, Tim Donoghue (industrial reporter with The Dominion), has recognised this and has gone beyond reporting simply the date that the next meeting will take place. While his efforts led to his incurring the wrath of the Prime Minister, the Cabinet, the Federation of Labour and the Employers' Federation, and ultimately the Press Council, The Dominion has received wide support for its stand from the media itself and the community at large - a clear demonstration that the public wants to be better informed about industrial relations issues. The media must take a lead in attempting to give that information and promote public debate about the issues in a serious rather than trivial and sensational manner. 